\title{
Survey of Occupational Musculoskeletal Pain and Injury in Canadian Optometrists
}

\author{
Kathryn Uhlman, \\ MBA, MScHQ \\ Queen's University \\ Vlad Diaconita, MD \\ Ivey Eye Institute \\ Department of Ophthalmology \\ Western University
}

\author{
Alexander Mao, \\ MD, OD, MPH \\ Ivey Eye Institute \\ Department of Ophthalmology \\ Western University \\ Rookaya Mather, \\ MD, FRCS(C) \\ Ivey Eye Institute \\ Department of Ophthalmology \\ Western University
}

\section{ABSTRACT}

Objective: To increase our understanding of occupational musculoskeletal (MSK) pain and injury among Canadian optometrists.

Methods: A voluntary, internet-based survey was distributed to all members of the Canadian Association of Optometry. Survey questions were adapted from the literature to identify the prevalence and significance of work-related MSK issues.

Results: Of the 121 optometrists (response rate $2.4 \%$ ) and 169 ophthalmologists (17\%; from a previous study) who participated, $61 \%$ and $50 \%$, respectively, reported work-attributed pain within the previous 12 months $(\mathrm{p}=0.06)$. The prevalence, location and severity of pain were similar to findings in the literature.

Conclusion: Many of the eye care professionals in our study were impacted by work-related MSK pain. More research is needed regarding the prevention and treatment of MSK pain in this population.

\author{
KEYWORDS \\ Occupational, Musculoskeletal, MSK, Pain, Injury, Ergonomics
}

\section{INTRODUCTION}

The risk of work-related musculoskeletal (MSK) pain among optometrists has become widely recognized by the profession and in the literature. ${ }^{1-3}$ Preliminary research on the impact of work-related MSK pain on eye care professionals has found that MSK pain and discomfort can lead optometry professionals to seek alternate employment, be hospitalized and seek other medical treatment. ${ }^{4}$ Other studies have found that improper work ergonomics can lead to poor productivity, disability and early retirement. ${ }^{5-7}$

Work-related injury is three times more likely to occur in the health and social service industries compared to the average across all industries. ${ }^{8} \mathrm{How}$ ever, the severity of the exposure to the risk of developing work-related MSK pain varies based on the healthcare environment. ${ }^{9}$ Recent studies have shown that there is higher prevalence of work-related MSK pain among eye care professionals; for example, Kitzmann et al. found that ophthalmologist have a $200 \%-300 \%$ higher prevalence of MSK pain than family physicians. ${ }^{10}$

Other studies have found a $62.1 \%-82.0 \%$ prevalence of work-related MSK pain among optometrists.,4 Both the location and prevalence of pain experienced by eye care professionals were similar across various studies. $^{4,5,10-12}$ Common areas of pain included the neck $(31.8 \%-51.7 \%$ of respondents), shoulder (11.0\%-50.2\%), lower back (26.0\%-50.6\%) and upper back (19.0\%-37.0\%). 
The Canadian Centre for Occupational Health and Safety defines the risk factors for work-related MSK disorders as follows: fixed or constrained body positions, continual repetition of movements, force concentrated on small parts of the body and a pace of work that does not allow sufficient recovery between movement. ${ }^{13}$ This was reflected in the study by Kitzmann et al., which identified several factors that contributed to work-related MSK pain among eye care professionals. ${ }^{10}$ These included repeatedly performing the same task, working in awkward/cramped positions, working in the same position for long periods and bending/twisting the back.

To our knowledge, no previous studies have examined the prevalence of work-related MSK pain among optometrists in Canada. The work of optometrists is closely related to that performed by ophthalmologists, but differences in practice patterns, demographics and patient populations may lead to a difference in MSK-related injuries. The purpose of this study was to investigate the prevalence and factors associated with work-related MSK pain among Canadian optometrists, and to compare these results to those among ophthalmologists. ${ }^{14}$

\section{METHODS}

A voluntary, internet-based survey (Survey Monkey Inc., San Mateo, CA, USA) was distributed to all optometrists registered with the Canadian Association of Optometry (CAO) through a list-serve email. A similar survey was sent to the Canadian Ophthalmology Society (COS) to survey Canadian ophthalmologists. The results of the ophthalmology respondents are published separately. ${ }^{14}$ The survey included a consent form that was presented to all respondents. Survey questions were adapted from the literature to identify the prevalence and significance of work-related MSK issues. No financial compensation was received for completion of the survey. Respondents could only complete the survey once from their respective IP address. This research was approved by the Western University Research Ethics Board.

\section{SURVEY}

The online survey collected information about the demographics and personal health of respondents, including age, gender, height, weight, exercise habits, years in practice and number of patients. The survey also asked respondents if they had sought treatment for previous MSK pain or injuries including but not limited to carpal tunnel syndrome, de Quervain's syndrome, bicep tendonitis and epicondylitis. Information on the use of medical management, allied health options (acupuncture, massage, physiotherapy) as well as surgical intervention was gathered for each diagnosis.

All respondents from the optometry and ophthalmology groups were asked, "In the last 12 months, have you experienced musculoskeletal pain that you attributed to your work in the clinic?". The survey also asked questions regarding specific areas of pain including "neck", "shoulder", "elbow", hand/wrist”, "upper back" and "lower back". For each area of pain, the respondent was asked to rate the pain as "none", "mild", "moderate" or "severe". The duration of the pain was also recorded as "none", "few hours", "few days", "few weeks" or "months".

Factors that contributed most to work-related MSK pain or injury were investigated through a Likert-like scale: "Does NOT contribute", "Minor contribution”, "Moderate contribution”, "Major contribution”, and "Not applicable to my practice". Answer options were chosen based on previous studies in the literature and from interviews with eye care providers.

A statistical analysis was conducted with SAS (SAS Institute, Cary, NC, USA) and Excel (Microsoft, Redmond, WA, USA) for both continuous and discrete variables. A multivariate logistic regression analysis was conducted for selected variables on an a priori basis to identify associations with MSK pain.

RESULTS

The survey was completed by 121 optometrists, with a response rate of $2.4 \%$.

RESPONDENT POPULATION CHARACTERISTICS

The characteristics of the study population are shown in Table 1 . The optometry group included a higher percentage of females (63.6\%) than the ophthalmology group (30.8\%).

The optometrists were slightly younger (44.1 years) than the ophthalmologists (48.7 years). However, the optometry group had more years in practice than the ophthalmology group (21.2 years vs. 16.6 years). The mean height and BMI were comparable between the groups. Both groups on average exercised just under 3 days a week. 
When asked to list prior MSK diagnoses, $62 \%$ of optometrists listed idiopathic low-back pain, followed by carpal tunnel syndrome (24\%). Idiopathic low back pain was also the most common diagnosis in the ophthalmologist group (31.4\%), followed by rotator cuff injury (18.9\%).

Table 1: Characteristics of the Respondents

\begin{tabular}{|c|c|c|c|c|c|c|c|c|}
\hline \multirow[t]{2}{*}{ Characteristic } & \multicolumn{4}{|c|}{ Optometrists $(\mathrm{n}=121)$} & \multicolumn{4}{|c|}{ Ophthalmologists (n=169) } \\
\hline & Mean & $\mathrm{SD}$ & Number & $\%$ & Mean & $\mathrm{SD}$ & Number & $\%$ \\
\hline Age & 44.09 & 10.63 & & & 48.73 & 13.08 & & \\
\hline Female & & & 77 & 63.64 & & & 52 & 30.77 \\
\hline Height & 1.71 & 0.11 & & & 1.74 & 0.09 & & \\
\hline BMI & 24.32 & 4.37 & & & 24.58 & 3.7 & & \\
\hline Days of exercise per week & 2.99 & 1.39 & & & 2.81 & 1.18 & & \\
\hline Years in Practice & 21.16 & 11.17 & & & 16.64 & 12.85 & & \\
\hline Patients per week & 69.47 & 28.96 & & & 139.81 & 70.26 & & \\
\hline Distance from work (kM) & 18.87 & 20.41 & & & 11.54 & 11.17 & & \\
\hline Transportation via Automobile to work & & & 112 & 92.56 & & & 145 & 85.8 \\
\hline \multicolumn{9}{|l|}{ Previous MS Issues } \\
\hline carpal tunnel syndrome & & & 29 & 23.97 & & & 14 & 8.28 \\
\hline de Quervain's syndrome & & & 9 & 7.44 & & & 6 & 3.55 \\
\hline bicep tendonitis & & & 11 & 9.09 & & & 8 & 4.73 \\
\hline epicondylitis & & & 15 & 12.4 & & & 17 & 10.06 \\
\hline cervical spine stenosis & & & 8 & 6.61 & & & 5 & 2.96 \\
\hline cervical disc disease & & & 10 & 8.26 & & & 23 & 13.61 \\
\hline rotator cuff injury & & & 24 & 19.83 & & & 32 & 18.93 \\
\hline frozen shoulder & & & 24 & 19.83 & & & 7 & 4.14 \\
\hline lumbar spine stenosis & & & 5 & 4.13 & & & 6 & 3.55 \\
\hline lumbar disc disease & & & 9 & 7.44 & & & 15 & 8.88 \\
\hline idiopathic low back pain & & & 75 & 61.98 & & & 53 & 31.36 \\
\hline Other & & & 15 & 12.4 & & & 24 & 14.2 \\
\hline
\end{tabular}

Ophthalmologist data from Ref. 14.

\section{Work-Related Musculoskeletal Pain}

Sixty-one percent of optometrists and $50 \%$ of ophthalmologists had experienced pain within the previous 12 months that could be attributed to their work in the clinic $(\mathrm{p}=0.06)$. The reported sites of pain, severity and duration are compared in Table 2 .

For optometrists, the most common site of pain was the shoulder (41\%), followed by the lower back (37\%), and the neck (34\%). Despite the high prevalence of shoulder pain, only $1 \%$ of the overall respondents reported that this pain was severe; $21 \%$ reported moderate pain and 19\% reported mild pain. Pain in the lower back pain was severe in $3 \%$ of the overall optometrist respondents, moderate in $10 \%$, and mild in $24 \%$. Pain of the neck was severe in $3 \%$ of the overall optometrist respondents, moderate in $14 \%$ and mild in $17 \%$. Similarly, the most common sites of pain for ophthalmologists were the neck (46\%), lower back (36\%) and shoulder (28\%). The rating of the pain as severe, moderate or mild for each site was similar in both groups. 
Table 2: Sites, Degree \& Duration of Pain

\begin{tabular}{|l|c|c|c|c|c|c|c|c|c|c|c|c|c|c|c|c|c|}
\hline Location & \multicolumn{1}{|c|}{ Prevalence (\%) } & \multicolumn{3}{|c|}{ Degree of pain (\% of respondents) } & \multicolumn{4}{|c|}{ Duration (\% of respondents) } \\
\hline & Optometrists & Ophthalmologists & \multicolumn{2}{|c|}{ Optometrists } & \multicolumn{2}{|c|}{ Ophthalmologists } & \multicolumn{3}{|c|}{ Optometrists } & \multicolumn{3}{|c|}{ Ophthalmologists } \\
\hline & & & Sev & Mod & Mild & Sev & Mod & Mild & Mo & Wk & D & H & Mo & Wk & D & H \\
\hline Neck & 34 & 46 & 3 & 14 & 17 & 2 & 17 & 27 & 8 & 4 & 18 & 3 & 12 & 2 & 17 & 13 \\
\hline Shoulder & 41 & 28 & 1 & 21 & 19 & 3 & 1 & 15 & 13 & 6 & 13 & 8 & 10 & 3 & 8 & 8 \\
\hline Elbow & 8 & 9 & 1 & 2 & 5 & 1 & 3 & 5 & 4 & 2 & 1 & 1 & 3 & 3 & 1 & 1 \\
\hline $\begin{array}{l}\text { Hand/ } \\
\text { Wrist }\end{array}$ & 32 & 18 & 1 & 10 & 21 & 2 & 6 & 1 & 8 & 9 & 7 & 7 & 5 & 3 & 4 & 4 \\
\hline $\begin{array}{l}\text { Upper } \\
\text { Back }\end{array}$ & 21 & 21 & 3 & 8 & 10 & 1 & 7 & 13 & 8 & 4 & 4 & 5 & 6 & 2 & 7 & 6 \\
\hline $\begin{array}{l}\text { Lower } \\
\text { Back }\end{array}$ & 37 & 36 & 3 & 10 & 24 & 4 & 13 & 19 & 8 & 12 & 12 & 5 & 9 & 4 & 11 & 11 \\
\hline
\end{tabular}

Sev, severe; Mod, Moderate; Mo, months; Wk, weeks; D, days; H, hours

\section{JOB FACTORS}

Optometrists were asked to rate several job factors in terms of whether they had a major, moderate, minor or no contribution to their work-related pain or injury. Most (67.8\%) of the optometrists identified "performing the same task repeatedly" as contributing to their work-related pain or injury, followed by "working in the same position" (60.3\%) and "slit lamp exams" (55.4\%). The factors that were considered to make a major contribution to workrelated pain were "performing the same task repeatedly" (39.7\%), "reaching or working over your head or away from your body" (29.8\%), and "working in the same position for long periods" (17.4\%). The other factors that were cited as contributing to work-related pain or injury are listed in Table 3.

Table 3: Factors Contributing to Work-Related MSK Pain in Optometrists

\begin{tabular}{|c|c|c|c|}
\hline \multirow[t]{2}{*}{ Factor } & \multicolumn{3}{|c|}{$\begin{array}{l}\text { Degree of contribution } \\
\text { (\% of respondents) }\end{array}$} \\
\hline & Any & $\begin{array}{l}\text { Moderate } \\
\text { or Major }\end{array}$ & Major \\
\hline Performing the same task repeatedly & 67.77 & 57.02 & 39.67 \\
\hline Working in the same position for long periods & 60.33 & 39.67 & 17.36 \\
\hline Reaching or working over your head or away from your body & 54.55 & 42.98 & 29.75 \\
\hline Working in cramped or awkward positions & 53.72 & 30.58 & 8.26 \\
\hline Continuing to work when injured or sick & 50.41 & 31.40 & 9.92 \\
\hline Insufficient breaks or pauses during the day & 51.24 & 28.93 & 9.92 \\
\hline Bending or twisting your back & 47.93 & 28.93 & 12.40 \\
\hline Working long or erratic hours & 44.63 & 24.79 & 9.09 \\
\hline Bending or twisting your neck & 44.63 & 23.14 & 9.92 \\
\hline Presbyopia / refractive error & 42.15 & 22.31 & 13.22 \\
\hline Slit lamp examination & 55.37 & 27.27 & 12.40 \\
\hline Indirect fundus examination & 50.41 & 19.83 & 6.61 \\
\hline
\end{tabular}


A multivariate logistic regression analysis of the data from optometrists showed that a self-reported history of cervical disc disease (OR 2.57, p=0.0312), rotator cuff injury (OR 1.91, p=0.0171), idiopathic low back pain (OR 1.79, $\mathrm{p}=0.0012$ ) or frozen shoulder (OR 1.74, $\mathrm{p}=0.0099)$ was most commonly associated with neck pain. Shoulder pain was associated with a self-reported history of frozen shoulder (OR 4.84, $\mathrm{p}=0.0004$ ), rotator cuff injury (OR 3.87, $\mathrm{p}=0.0002)$ or idiopathic low back pain (OR 1.94, $\mathrm{p}=0.0009)$. Elbow pain was associated with a history of epicondylitis (OR 3.28, p=0.0073) or bicep pain (OR 2.84, p=0.0004), while wrist and hand pain was associated with idiopathic low back pain (OR 1.77, p=0.0005). Lower back pain was associated with idiopathic low back pain (OR 2.38, $\mathrm{p}<0.0001)$ (Table 4).

Table 4: Multiple Logistic Regression in Optometrists

\begin{tabular}{|c|c|c|c|c|c|}
\hline $\begin{array}{l}\text { Type of occupational } \\
\text { MSK pain }\end{array}$ & Association & Odds Ratio & CI & p-value & $\mathbf{N}$ \\
\hline \multirow{5}{*}{ Neck Pain } & Cervical Disc Disease & 2.57 & $(1.089-6.049)$ & 0.0312 & \multirow{5}{*}{41} \\
\hline & Age & 0.95 & $(0.905-0.992)$ & 0.0202 & \\
\hline & Rotator Cuff Injury & 1.91 & $(1.122-3.239)$ & 0.0171 & \\
\hline & Frozen Shoulder & 1.74 & $(1.143-2.660)$ & 0.0099 & \\
\hline & Idiopathic Low Back Pain & 1.79 & $(1.259-2.545)$ & 0.0012 & \\
\hline \multirow{4}{*}{ Shoulder Pain } & Age & 0.93 & $(0.885-0.978)$ & 0.0046 & \multirow{4}{*}{71} \\
\hline & Rotator Cuff Injury & 3.87 & $(1.896-7.907)$ & 0.0002 & \\
\hline & Frozen Shoulder & 4.84 & (2.014-11.616) & 0.0004 & \\
\hline & Idiopathic Low Back Pain & 1.94 & $(1.310-2.873)$ & 0.0009 & \\
\hline \multirow{2}{*}{ Elbow Pain } & Epicondylitis & 3.28 & $(1.690-6.369)$ & 0.0004 & \multirow{2}{*}{111} \\
\hline & Bicep Pain & 2.84 & $(1.325-6.082)$ & 0.0073 & \\
\hline Hand/Wrist Pain & Idiopathic Low Back Pain & 1.77 & $(1.282-2.452)$ & 0.0005 & 83 \\
\hline Upper Back Pain & Age & 0.93 & $(0.876-0.977)$ & 0.0051 & 95 \\
\hline Lower Back Pain & Idiopathic Low Back Pain & 2.38 & $(1.684-3.369)$ & $<0.0001$ & 75 \\
\hline
\end{tabular}

\section{DISCUSSION}

In this study, $61 \%$ of optometrists had experienced MSK pain attributed to their work within the previous 12 months, compared to $50 \%$ of ophthalmologists. These results are similar to those reported by Gromacki et al.: $62.1 \%$ of optometrists experienced MSK pain throughout their careers. ${ }^{3}$ However, we found a lower prevalence of MSK pain in optometrists than a previous study by Long and her team. ${ }^{4}$ Long found that $82 \%$ of optometrists reported work-related physical discomfort over the past 12 months. This higher percentage of respondents reporting physical discomfort could be attributed to use of the term "discomfort," which likely includes a broader range of MSK issues than "pain" in the minds of respondents. Our findings are closer to those in other studies on MSK pain in eye care professionals, including those by Hyer et al. ${ }^{11}$ (prevalence of 62.4\%), Al-Marwani Al-Juhani et al. ${ }^{15}$ (72\%), and Kitzmann et al. ${ }^{10}$ (11\%-46\% depending on the body area).

Although no other study has directly compared the prevalence of MSK pain in optometrists and ophthalmologists, Al-Marwani Al-Juhani et al. ${ }^{15}$ compared the prevalence of neck and back pain among ophthalmologists and other eye care providers, including a small subset of optometrists (11 of the 165 respondents). They found higher percentages of pain in optometrists (82\%) and all allied eye care providers (72\%) than in ophthalmologists (67\%). This is consistent with our findings. 
Although the rates of MSK discomfort and pain can be compared among the studies noted, the results are not directly comparable due to the various time frames of experienced pain. Some studies, such as that by Al-Marwani Al-Juhani et al. ${ }^{15}$ did not specify a time frame when respondents were asked if they had experienced MSK issues attributable to their work. ${ }^{4}$ Kitzmann et al. ${ }^{10}$ specified a narrow time frame of MSK pain (the past 30 days), which may have decreased the percentage of respondents who reported pain.

The average age of optometrists in our study (44.1 years) is comparable to those in other studies.,10,11 Greater age was not associated with MSK pain among our respondents.

In the study by Long et al., ${ }^{4}$ optometrists reported discomfort most often in the neck, (51.7\%), shoulder (50.2\%) and lower back (45.9\%). These three sites also had the highest prevalence of pain in our study, although with a different ranking (41\% in the shoulder, $37 \%$ in the lower back, and 34\% in the neck). Similarly, the most common sites of pain reported by ophthalmologists in our study were the neck (46\%), lower back (36\%), and shoulder (28\%).

Al-Marwani Al-Juhani et al. ${ }^{15}$ investigated the severity of work-related MSK discomfort and pain. Among eye care professionals who had experienced work-related MSK pain, this pain was severe in 10\%, moderate in $34 \%$, and mild in 53\%. In our study, among optometrists who experienced work-related shoulder pain, most (53.7\%) reported the pain as moderate to severe.

Al-Marwani Al-Juhani et al. ${ }^{15}$ also found that the prevalence of back pain was $23.4 \%$ lower for individuals who exercised a minimum of three times a week, compared to those who did not exercise. Long et al. ${ }^{4}$ found that females were more likely to experience work-related MSK discomfort than males. Gender was not associated with MSK pain among our respondents.

\section{JOB FACTORS}

When investigating the job factors that contributed to work-related MSK pain among ophthalmologists, Kitzmann et $\mathrm{al}^{10}$ found that the three most commonly cited factors were "working in awkward/cramped positions" (57\%), "working in the same position for long periods" (55\%) and "performing the same task repeatedly" (45\%). We obtained similar findings in optometrists: the three most commonly cited factors were "performing the same task repeatedly" (67.8\%), "working in the same position for long periods" (60.3\%), and "slit lamp exams" (55.4\%). In our previous study in ophthalmologists, the most common causes of work-related pain were "performing the same task repeatedly" (58.6\%), "working in cramped or awkward positions" (52.1\%) and "working long or erratic hours" $(50.3 \%)$.

\section{LIMITATIONS OF THE STUDY}

The present results are limited by the low response rate of optometrists (2.4\%), which raises the question of whether the results accurately reflect the population studied. A response bias may be another limitation, since people in pain may have been more likely to complete the survey than the general population. Furthermore, while only $52.9 \%$ of optometrists in Canada are females, ${ }^{16} 63.6 \%$ of our respondents were female. Finally, our questionnaire is vulnerable to both a recency bias and a severity bias, as recent and more severe injuries would be more likely to be recalled by respondents.

\section{HOURS OF WORK LOST}

It is important to understand the characteristics of work-related MSK pain in eye care professionals because such pain has been shown to impact their careers. Work-related MSK pain can lead to lost work. In a study of pediatric orthopedic surgeons, $51 \%$ of those with careers of 21 to 30 years had taken time off work due to MSK injuries. ${ }^{17}$ In a study of optometrists who had experienced work-related MSK discomfort, $32 \%$ had stopped working as a result of the pain, and $4 \%$ of respondents reported that they had stopped working as an optometrist altogether. ${ }^{1}$ Another study found that poor work ergonomics leads to disability, poor work productivity and early retirement. ${ }^{5}$

\section{EXERCISE AND TRAINING}

More research is needed to determine best practices for the prevention and treatment of MSK pain among eye care professionals. In a literature review, moderate evidence suggested that exercise training could improve strength and endurance, leading to positive effects on MSK outcomes in healthcare professionals. ${ }^{18}$ A study of dentists in the Netherlands suggested that implementing recommendations for proper work-related posture helped to improve Musculoskeletal Disorders (MSD), with $84 \%$ of respondents reporting that it partially or fully reduced their MSD. ${ }^{19}$ 
Other interventions for prevention, including optimization of current instruments and devices, and proper education could limit the prevalence of MSK pain among eye care professionals. ${ }^{20}$

\section{CONCLUSION}

In conclusion, the results of our study were consistent with other literature that focused on MSK pain among eye care professionals. Among the optometrists studied, 61\% had experienced work-attributable MSK pain within the previous 12 months. The most common areas of pain were the shoulder, lower back and neck. The prevalence, location and severity of pain were similar to those in the literature. More research is needed regarding the prevention and treatment of work-related MSK pain in eye care professionals, which can be career-limiting. •

\section{REFERENCES}

1. Long J, Burgess-Limerick R, Stapleton F. Personal consequences of work-related physical discomfort: An exploratory study. Clin Exp Optom 2014;97(1):30-5.

2. Newman BY. Ergonomics and the optometrist. Optometry 2005;76(2):77.

3. Gromacki S, Wicker D, Leung H. Ergonomics in eye care. Optom Vis Sci 2002;79 (Supplement):101.

4. Long J, Naduvilath TJ, Hao L, et al. Risk factors for physical discomfort in Australian optometrists. Optom Vis Sci 2011;88(2):317-26.

5. Honavar S. Head up, heels down, posture perfect: Ergonomics for an ophthalmologist. Indian J Ophthalmol 2017;65(8):647.

6. Soueid A, Oudit D, Thiagarajah S, Laitung G. The pain of surgery: Pain experienced by surgeons while operating. Int J Surg 2010;8(2):118-20.

7. Sivak-Callcott JA, Mancinelli CA, Nimbarte AD. Cervical occupational hazards in ophthalmic plastic surgery. Curr Opin Ophthalmol 2015 Jul;26(5):392-8.

8. The Association of Workers' Compensation Boards of Canada. National Work Injury, Disease and Fatality Statistics (Rep.) 2016.

9. Waters T, Collins J, Galinsky T, Caruso C. NIOSH research efforts to prevent musculoskeletal disorders in the healthcare industry. Orthop Nurs 2006 Nov-Dec;25(6):380-9.

10. Kitzmann AS, Fethke NB, Baratz KH, Zimmerman MB, Hackbarth DJ, Gehrs KM. A survey study of musculoskeletal disorders among eye care physicians compared with family medicine physicians. Ophthalmology 2012;119(2):213-20.

11. Hyer JN, Lee RM, Chowdhury HR, Smith HB, Dhital A, Khandwala M. National survey of back \& neck pain amongst consultant ophthalmologists in the United Kingdom. Int Ophthalmol
2015;35(6):769-75

12. Marx JL, Wertz FD, Dhimitri KC. Work-related musculoskeletal disorders in ophthalmologists. Tech Ophthalmol 2005;3(1), 54-61.

13. Canadian Centre for Occupational Health. Work-related Musculoskeletal Disorders (WMSDs): OSH Answers. 2018, May 11. Retrieved from https://www.ccohs.ca/oshanswers/diseases/rmirsi. html

14. Diaconita V, Uhlman K, Mao A, Mather R. Survey of occupational musculoskeletal pain and injury in Canadian ophthalmology. Can J Ophthalmol 2018; In press.

15. Al-Marwani Al-Juhani M, Khandekar R, Al-Harby M, Al-Hassan A, Edward DP. Neck and upper back pain among eye care professionals. Occup Med (Lond) 2015 Dec;65(9):753-7.

16. Canadian Institute for Health Information. Canada's Health Care Providers: Provincial Profiles, 2007 to 2016 - Data Tables(Rep.) 2016.

17. Alzahrani MM, Alqahtani SM, Tanzer M, Hamdy RC. Musculoskeletal disorders among orthopedic pediatric surgeons: An overlooked entity. J Child Orthop 2016 Oct;10(5):461-6.

18. Tullar JM, Brewer S, Amick BC, et al. Occupational safety and health interventions to reduce musculoskeletal symptoms in the health care sector. J Occup Rehabil 2010 Jun;20(2):199-219.

19. Lavender SA, Sommerich CM, Johnson MR, Radin Z. Developing ergonomic interventions to reduce musculoskeletal disorders in grocery distribution centers. Proc Hum Factors Ergon Soc Annu Meet 2010;54(15):1229-33.

20. Marx JL. Ergonomics: Back to the future. Ophthalmology 2012;119(2):211-2. 